\title{
Crop Phenotyping for Wheat Yield and Yield Components against Drought Stress
}

\author{
K. Pouri ${ }^{1}$, A. Sio-Se Mardeh ${ }^{2 *}$, Y. Sohrabi ${ }^{2}$ and A. Soltani ${ }^{3}$ \\ ${ }^{1}$ Faculty of Agriculture, University of Kurdistan, Sanandaj, Iran \\ ${ }^{2}$ Department of Agronomy, University of Kurdistan, Iran \\ ${ }^{3}$ Department of Agronomy, Gorgan University of Agricultural Sciences, Iran \\ (Received 17 August 2018; 31 January 2019; \\ Communicated by A. Goyal)
}

\begin{abstract}
Water deficit is a most limiting factor for wheat in rain-fed agricultural systems worldwide. The effects of drought stress on some root features and yield and yield components in wheat (Trticum aestivum L.) were carried out in a factorial experiment based on completely randomized design, under greenhouse condition. The four experimental irrigation regimes, irrigation after $75 \%$ of the water was depleted (control), irrigation after $65 \%$ of the water was depleted (mild stress), irrigation after 55\% of the water was depleted (moderate stress) and irrigation after $45 \%$ of the water was depleted (severe stress) were randomized for the main plots. The subplot treatments included eight wheat genotypes. Results showed that Interaction Drought stress with Variety had significantly affected on Total Root Volume and Dry Matter, Number of Tiller and also Shoot Dry Matter. Value of Total Root Volume and Dry Matter, Shoot Dry Matter and Number of Tiller in irrigated varieties were more than rainfed in whole of Drought stresses. N-87-20 variety had most amounts of Total Root Dry Matter, Total Root Volume (exception of control) in all of stresses and control. Root properties influence on yield and other morphological traits of wheat. Stress intensification increase root growth than plant organ so that wheat root can uptake water from soil to compensate damage caused by stress.
\end{abstract}

Keywords: drought stress, variety, root, yield

\section{Introduction}

Drought is the most important limiting factor of wheat production across the world. Terminal drought which occurs during post-anthesis significantly reduces wheat grain yield due to induce grain abortion and affects grain filling, resulting in shrivelled grain and thus, reducing grain yield (Budak et al. 2013). Drought may affect wheat growth during all phonological stages. Furthermore, drought stress influenced seed germination, seedling growth, dry matter partitioning and root growth, root depth and extension. Grain yield in wheat is mainly correlated with yield components and it was reported that any reduction in the yield component leads to a reduction in the final yield (Farooq et al. 2014). Seed filling had high sensitivity to environmental conditions. Evidence on other crops showed that varieties could be developed for increase yield under water limiting

*Corresponding author; E-mails: mehmesh@outlook.com; a33@uok.ac.ir 
condition (Hayat et al. 2012). As modern agriculture is increasingly shifted to marginal lands and drought events become more frequent and intense, specific root morphological traits that can improve drought tolerance and sustain yields in suboptimal conditions hold immense potential (Placido et al. 2013). The root system has morphological and physiological plasticity in response to adverse different environments. A large root system can result in rapid soil water consumption, which may not be favorable in non-irrigated arid and semiarid areas. While roots are potentially important for plants under drought stress, they do not contribute to drought adaptation in all stress conditions. a maximum reasonable variation within species in the amount of available water that can be gained by deep rooting is about $30 \mathrm{~mm}$, equivalent to about $30 \mathrm{~cm}$ soil depth (Kano et al. 2011).

Moderate drought stress can significantly increase the root length density of the soil profile (Learnmore et al. 2016). Several researchers (Reynolds et al. 2005) have suggested that a deep, wide-spreading and much-branched root system is essential in the design of drought-tolerant crops. On the other hand, Lonbani and Arzani (2011) suggested that small root systems could provide benefits in water-limited situations through improved water use efficiency. In most wheat crops, root length density in the surface layers is $3-5 \mathrm{~cm} \cdot \mathrm{cm}^{3}$ and thus, in theory, exceeds that required to extract crop available water (Hayat et al. 2012).

Excess root length may be a carbon cost to grain, especially if grown towards the end of the season when carbon is limiting, and rainfall events are short and evaporate rapidly before root water uptake. Despite the increasing interest in individual morphological root traits and their functional implications for water capture under water-deficient conditions, there is still little consensus on whether a large root system contributes to wheat adaptation in water-limited environments. Consequently, the objective of the present study was to study the effect of drought stress on the responses of shoot, roots and yield traits of wheat.

\section{Materials and Methods}

Two-year experiment (2015-2016 and 2016-2017) were conducted in a glasshouse at Faculty of Agriculture, University of Agricultural Sciences and Natural Resources Gorgan Iran $\left(54^{\circ} 10^{\prime} 43,36^{\circ} 84^{\prime} \mathrm{N}\right)$, in order to investigate the effects of drought stress on some root features, yield and yield components in wheat. The seeds of eight wheats (Triticum aestivum L.) cultivars (N-87-20, Gonbad, Morvarid and N-91-8 termed as irrigated cultivar; Kouhdasht, Karim, Ghabous and Aftab named as rain fed cultivars which were provided by Seed and Plant Certification and Registration Institute, Table 1) were surface sterilized by $10 \%$ chlorox solution within $1 \mathrm{~min}$, washed thoroughly, and then imbibed in distilled water (Dolatabadian et al. 2012) and grown in uniformed pots $(23 \times 30 \mathrm{~cm})$ that contained clay-loam soil (35\% clay, 35\% silt and 30\% sand) in a glasshouse under conditions of $14 \mathrm{~h}$ light $/ 10 \mathrm{~h}$ dark and natural light with of $250 \mu \mathrm{mol} \mathrm{m} \mathrm{m}^{-2} \mathrm{~s}^{-1}$ irradiance, $25 \pm 2{ }^{\circ} \mathrm{C} / 15 \pm 2{ }^{\circ} \mathrm{C}$ day/night temperature and $60 \pm 5 \%$ relative humidity. Fifteen seeds were planted in each pot and after full germination; the number of plants was reduced to ten seedlings per pot. According to soil physicochemical analysis results and recommen- 
Pouri et al.: Drought Change Phenotype and Yield of Wheat

\begin{tabular}{|c|c|c|c|c|c|c|c|c|}
\hline 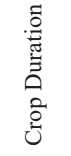 & $\begin{array}{l}n \\
= \\
2 \\
\varrho\end{array}$ & $\begin{array}{l}n \\
= \\
n \\
n\end{array}$ & $\begin{array}{l}\stackrel{n}{=} \\
\overline{1} \\
\text { है }\end{array}$ & $\begin{array}{l}n \\
= \\
n \\
n \\
=\end{array}$ & 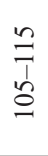 & 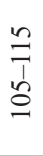 & $\begin{array}{l}n \\
\overline{1} \\
n \\
2\end{array}$ & $\begin{array}{l}n \\
\Rightarrow \\
n \\
2\end{array}$ \\
\hline 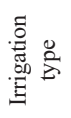 & 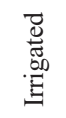 & 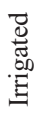 & 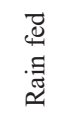 & 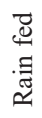 & 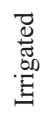 & 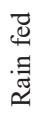 & 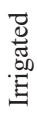 & 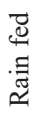 \\
\hline 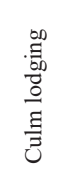 & 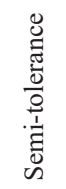 & 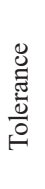 & 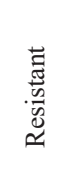 & 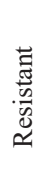 & 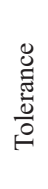 & 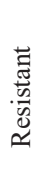 & 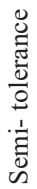 & 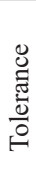 \\
\hline 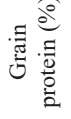 & $\simeq$ & $\simeq$ & $\simeq$ & $\simeq$ & $\simeq$ & $\simeq$ & $\simeq$ & $\exists$ \\
\hline 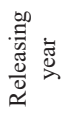 & 혹 & $\stackrel{\circ}{\stackrel{\sim}{\sim}}$ & $\stackrel{ \pm}{\stackrel{\sim}{\sim}}$ & $\stackrel{m}{\stackrel{\sim}{\sim}}$ & $\overline{\vec{i}}$ & $\vec{\nabla}$ & $\stackrel{\infty}{\stackrel{\sim}{े}}$ & ஓి \\
\hline 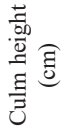 & $\begin{array}{l}\frac{8}{1} \\
\frac{1}{2}\end{array}$ & $\begin{array}{l}\stackrel{\circ}{\exists} \\
\stackrel{1}{\circ}\end{array}$ & $\begin{array}{l}0 \\
\infty \\
\infty \\
\infty\end{array}$ & \& & $\begin{array}{l}\stackrel{2}{6} \\
\frac{1}{2}\end{array}$ & $\frac{n}{\infty}$ & $\begin{array}{l}\stackrel{ }{\exists} \\
\frac{1}{2}\end{array}$ & 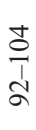 \\
\hline 产 & 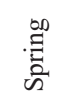 & 告 & 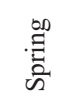 & 号 & 范 & 品 & $\begin{array}{l}\text { है } \\
\text { है } \\
\text { है }\end{array}$ & है \\
\hline 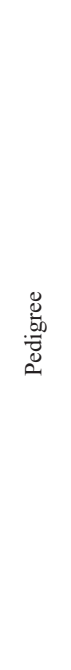 & 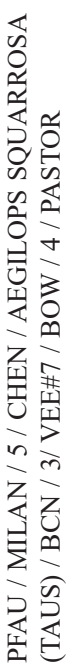 & 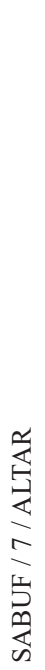 & 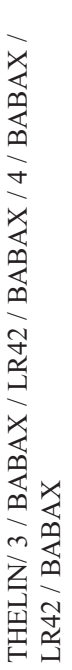 & 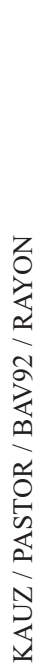 & 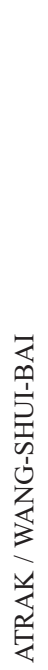 & 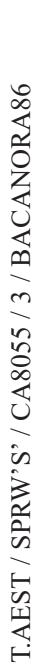 & 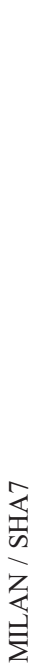 & 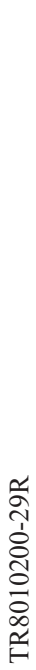 \\
\hline 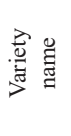 & $\frac{\infty}{\frac{1}{a}}$ & $\begin{array}{l}\stackrel{1}{1} \\
\frac{1}{\infty} \\
i \\
z\end{array}$ & 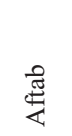 & 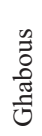 & 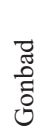 & 吉 & 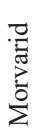 & 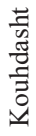 \\
\hline
\end{tabular}


dations, phosphorus at the rate of $60 \mathrm{~kg} \mathrm{ha}^{-1}$ in the form of superphosphate triple and potassium at the rate of $20 \mathrm{~kg} \mathrm{ha}^{-1}$ in the form of potassium sulphate were applied before seed sowing while nitrogen fertilizer at the rate of $150 \mathrm{~kg} \mathrm{ha}^{-1}$ in the form urea was applied at three different stages; one-third before seed sowing and mixed into the soil, onethird at stem elongation stage and one-third at flowering stage by spreading the fertilizer onto the soil surface just before irrigation. The plants were irrigated at field capacity level.

The experimental design was a complete randomized design in $8 \times 4$ factorial with three replications (Keshavarza and Sadegh Ghol Moghadam, 2017). Drought stress was imposed at stem elongation until full maturity by withholding water supply until the soil moisture was reduced. Water shortage treatment were maintained without watering until the soil water potential reached $75.5 \% \mathrm{FC}$ (control), $65 \% \mathrm{FC}$ (mild stress), $55.5 \% \mathrm{FC}$ (moderate stress) and $55.5 \% \mathrm{FC}$ (severe stress). After that the plants were irrigated. Irrigation water needed prior to irrigation was estimated base on the soil water content $(\theta \mathrm{i})$ using by TDR method (Time Domain Reflectometry, model 4593, soil moisture equipment, Santa Barbara) and effective rooting depth (D, $0.3 \mathrm{~m}$ here) according to the following equation (1) (Cuenca 1989):

$$
\mathrm{Vw}:(\theta \mathrm{F} \cdot \mathrm{C}-\theta \mathrm{i}) \times \mathrm{D} \times \mathrm{A}
$$

where, $\theta \mathrm{F} \cdot \mathrm{C}$ is the volume of soil moisture at field capacity and $\mathrm{A}$ is the pot area $(\mathrm{m})$. A TDR probes were inserted in to vertical holes of $0.50 \mathrm{~cm}$ in diameter and $8 \mathrm{~cm}$ depth. Data on volumetric water content were collected daily prior to set the experiment to calibrates before to seed sowing and during the growing season to calculated the time of irrigation. The amount of water irrigation applied was according to the soil deficit to bring it back to field capacity.

Harvest of each genotype was done at full maturity (13\% seed moisture, 110 days after planting). When each genotype reached the appropriate stage (physiological maturity), they were cut at ground level. The plants were harvested and the roots and shoots were separated and washed with deionized distilled water. Various root traits as root depth $(\mathrm{cm})$ and total root volume $\left(\mathrm{cm}^{3}\right)$, total root dry matter $(\mathrm{g})$, shoot dry matter $(\mathrm{g})$, plant height $(\mathrm{cm})$, root/shoot ratio, peduncle length $(\mathrm{mm})$, spike length $(\mathrm{mm})$ and number of tiller were measured. For the estimation of plant dry matter, the plants were dried at $70{ }^{\circ} \mathrm{C}$ for $48 \mathrm{~h}$. The 1000 kernel weight $(\mathrm{g})$, grain yield $(\mathrm{kg} / \mathrm{ha})$ and plant biomass $(\mathrm{kg} / \mathrm{ha})$ were determined at maturity (110 days after planting) on 10 randomly selected plants from each replication.

The present data are the means value of two independent experiments. All data were subjected to two-way analysis of variance (ANOVA) and expressed as the means. Differences among treatments were analyzed by Least significant difference (LSD) test at $\mathrm{P} \leq 0.05$ (Keshavarz and Sadegh Ghol Moghadam 2017). Experiments were repeated twice and the pooled data were analyzed using SAS (SAS release 9.0,2002) because the results followed a similar trend and the variances were homogeneous. General correlations between parameters were examined with Pearson's correlation coefficients. Corre- 
lations were considered statistically significant and are indicated at ns, not significant; * at $\mathrm{P} \leq 0.05$ and $* *$ at $\mathrm{P} \leq 0.01$. Principal component analysis (PCA) was performed to visualize the similarities or differences in all traits under different drought stress using SAS and the results of this analysis are presented as bi-plots.

\section{Results}

Drought stress had significantly affected on Total Root Dry Matter, Shoot Dry Matter, Peduncle Length, Number of Tiller, 1000 grain weight, Biomass Yield and Root/shoot ratio in 1\% level and Plant Height and Grain Yield in 5\% level. Differences between Variety for some morphological traits, yield and yield components were significant $(\mathrm{P} \leq 0.01)$. Interaction Drought stress with Variety had significantly affected on Total Root Dry Matter, Total Root Volume and Number of Tiller in 1\% level and also Shoot Dry Matter in 5\% level (Table S1*).

As per Table S2 shows that the highest amount of Plant Height, Peduncle Length, 1000 grain weight, Grain Yield and Biomass Yield were seen in control treatment which had significant difference with severe stress treatment. There was significant difference between control with other treatments for R/Sh ratio. Results showed that Plant Height, Peduncle Length, 1000 Grain weight, Grain Yield and Biomass Yield in Severe Stress has decreased by $10.99,19.53,8.52,14.33$ and 35.68 percent relative to control treatment. Root/shoot ratio increased by 155.55 percent in severe stress than normal condition. Increasing stress reduced Height, Peduncle Length, 1000 Grain weight, Grain Yield and Biomass Yield trend but improved Root/shoot ratio trend.

Varieties had a significant effect on some morphological traits, yield and yield components in wheat. Since varieties of N-87-20, Gonbad, Morvarid and N-91-8 were irrigated and Kouhdasht, Karim, Ghabous and Aftab were rain-fed variety. Totally, irrigated varieties had more values of morphological traits, yield and yield components in relative to rainfed. Among rainfed varieties, Aftab had most values of plant height, root depth, Peduncle Length, Spike length, 1000 Grain weight, Grain Yield and Biomass Yield. Highest and lowest values of these feathers were related to N-87-20 and Karim varieties, respectively and also, there was significant difference between N-87-20 and Karim (Table S3).

Interaction irrigation regime and cultivars shows that value of Total Root Dry Matter, Total Root Volume, Shoot Dry Matter and Number of Tiller in irrigated varieties were more than rainfed in whole of drought stresses. Among of irrigated varieties, N-87-20 had most amounts of Total Root Dry Matter, Total Root Volume (exception of control) and Shoot Dry Matter (exception of Severe Stress) in all of stresses and control. Number of Tiller in N-87-20 was more than other varieties in no and severe stress.

In control, the most Total Root Volume, Shoot Dry Matter and Number of Tiller in rainfed varieties was related to Aftab. In mild stress, Kouhdasht variety had most value of Total Root Dry Matter, Total Root Volume and Shoot Dry Matter in between rainfed varieties. Aftab had more Total Root Volume and Shoot Dry Matter compared to other rainfed varieties in Moderate Stress. Among of rainfed varieties, Ghabous and Aftab varieties

*Further details about the Electronic Supplementary Material (ESM) can be found at the end of the article. 
had most Total Root Dry Matter and Total Root Volume in severe stress, respectively. The least Total Root Dry Matter and Total Root Volume were obtained with control and Karim treatment (Table S4). For whole of varieties (exception of Aftab), there was an increasing trend in Total Root Volume from control to moderate stress increased and then reduced in severe stress.

\section{Correlation between some morphological traits, yield and yield components in wheat}

There were high and significant correlation between Root depth, Total Root Dry Matter and Total Root Volume with Grain Yield, Biomass Yield, Root/shoot ratio and Number of Tiller in control treatment. The significant correlation was obtained between spike length with Total Root Dry Matter and Total Root Volume which were 0.617 and 0.600, respectively. Correlation between Root/shoot ratio, Spike length and Number of Tiller with Grain Yield were 0.721, 0.503 and 0.610, respectively (Table S5). It shows that the effects of Root/shoot ratio, Number of Tiller on Grain Yield were greater than Spike length in control treatment.

Table S6 showed that most correlation Root depth, Total Root Dry Matter and Total Root Volume was seen by Grain Yield and Shoot Dry Matter $(\mathrm{P} \leq 0.05)$. There were high correlations between Spike length with Total Root Dry Matter $(\mathrm{P} \leq 0.05,0.779)$ and Total Root Volume $(\mathrm{P} \leq 0.05,0.661)$. Correlations of 1000 grain weight, Shoot Dry Matter and Spike length with Grain Yield were $(\mathrm{P} \leq 0.05,0.518),(\mathrm{P} \leq 0.05,0.629)$ and $(\mathrm{P} \leq 0.05$, 0.451), respectively. In Mild Stress treatment, the impact of shoot dry matter on grain yield was greater compared to 1000 grain weight and Spike length.

Correlation between Root depth, Total Root Dry Matter and Total Root Volume with Grain Yield was $0.553,0.596$ and 0.608 respectively. There was significant correlation between Grain Yield and 1000 Grain weight $(\mathrm{P} \leq 0.05,0.475)$ in Moderate Stress (Table S7).

Unlike other treatments, the highest correlation between Root depth, Total Root Dry Matter and Total Root Volume was seen with Number of Tiller. In severe stress treatment, correlation of grain yield with Spike length was greater than other plant features $(\mathrm{P} \leq 0.05$, 0.572) (Table S8). In general, correlations in this treatment were less relative to other treatments. In moderate and severe stress conditions, value of correlation of RD with TRDM, TRV, SDM, R/SH, PH, PDL, SL, FTN, GW, BY and GY reduced with other trait. Correlation between RD with BY, SDM, TRV and TRDM was highest in control, mild, moderate and severe stress, respectively. In control, mild, moderate and severe stress, correlation of TRDM with $\mathrm{R} / \mathrm{SH}, \mathrm{R} / \mathrm{SH}, \mathrm{TRV}$ and $\mathrm{R} / \mathrm{SH}$ was greatest value. TRV had greatest correlation with FTN, SDM, GY and FTN in control, mild, moderate and severe stress condition, respectively. Correlation of GY with R/SH, TRV, TRV and SL was highest value in control, mild, moderate and severe stress, respectively.

The results of the principal components analysis showed that at all levels of stress, the two components had an Eigen value higher than one and had the highest level of variance. At the stress level of s1, the first and second components had $87 \%$ of the total variance. In the first component, all traits except the $\mathrm{PH}$ had the highest load factor in the positive 
direction and also, in the second component, the $\mathrm{PH}$ had the highest amount of load factor. With increasing stress, the contribution of the first component decreased and the second component was added so that at the last level of stress the first component has 65 and the second component has 14\% relative variance. At S2, the R/SH ratio had the lowest factor load in the first component. In contrast, the highest load factor in the second component was related to the FTN trait. All traits except SDM, R/SH and FTN assign the highest load factor in the first component at S3 stress level. In contrast, the R/SH ratio showed the highest factor load in the second component. Finally, at the last stress level (s4), all traits (exception of the SDM) showed the highest load factor. In contrast, the least load factor was seen in the TRDM and SDM traits (Table S9).

\section{Discussion}

In this research, drought stress and varieties had significant effect on yield and component yield of wheat. But interaction of drought stress and varieties had only significant effect on Total Root Dry Matter, Total Root Volume, Number of Tiller and Shoot Dry Matter. Othmani et al. (2015) found that there was a significant effect of water regimes on shoot dry weight, tillers and spikes dry weight, number of kernels/spike and spike weight $(\mathrm{P} \leq 0.001)$ and also root volume, root dry weight/shoot dry weight ratio, thousand-kernel weight $(\mathrm{P} \leq 0.005)$ As well as the interaction of water regimes and varieties had significant effects on root volume $(\mathrm{P} \leq 0.001)$ and shoot dry weight $(\mathrm{P} \leq 0.005)$. Whereas Guendouz et al. (2014) revealed the different varieties of wheat have different drought responses. While Khakwani et al. (2012) found that wheat varieties had significant differences on all physiological and yield traits.

The highest amount of Plant Height, Peduncle Length, 1000 grain weight, Grain Yield and Biomass Yield was related to Control, along with lowest amount of R/SH ratio. Plant Height, Peduncle Length, 1000 Grain weight, Grain Yield and Biomass Yield trend was lowered by stress intensification but Root/shoot ratio trend was increased. Stress intensification leads to increase root growth than shoot so that wheat root can uptake water and nutrition from soil to compensate damage caused by stress. Large root system is necessary for crops growth in drought conditions to uptake more water from soil and relief drought stress (Palta et al. 2011; Ehdaie et al. 2012). Small root system could have a positive effect on grain yield in drought stress (Zhu and Zhang 2013). Sun et al. (2014) said that roots play an important role in water uptake, photosynthetic rate, which affected on yield, especially in the water-limited situations. Ehdaie et al. (2012) reported that significant reduction in plant growth and shoot production due to drought stress reduces wheat yield by up to $50 \%$.

The greatest and least amount of plant height, root depth, Peduncle Length, Spike length, 1000 Grain weight, Grain Yield and Biomass Yield was observed in N-87-20 and Karim varieties, respectively. N-87-20 variety with increasing root depth and root/shoot ratio enhanced grain yield. Value of root depth and Root/shoot ratio in N-87-20 relative to Karim increased by 19.88 and 80 percent, respectively, which caused improve grain yield by 33.21 percent. N-87-20 and Karim varieties is considered as irrigated and rainfed 
varieties. Also, irrigated Varieties had more values of morphological traits, yield and yield components in relative to rainfed. Atta et al. (2013) reported that the root growth in soil high moisture was more than low moisture. According to Wasson et al. (2012), wheat varieties with a deep root system, increased and reduced root density at depth and surface, respectively that enhanced wheat yield of rainfed and crops respond positively to deep water to fill the grain.

Comparison of no and severe stresses in all of varieties (exception of N-87-20) shows that value of Total Root Dry Matter improved by stress. In fact, the root system is the main member of the plant to absorb water and nutrients that affect plant growth and seed production.

Plants have to improve Total Volume and Dry Matter of Roots to eliminate limitations of drought stress so that can enhance their contact with soil and uptake more water. Varieties can be suitable and useful for growth under stress condition which able to product long and bulky roots (such as N-87-20) because they can uptake their requirement water from land depths by long and bulky roots and reduce less their yield. According to Fang et al. (2017), root system adaptive to drought stress was increasing with genetic improvements because wheat varieties produced different root features under well-watered and water-stressed conditions. Some varieties improve more value of topsoil root mass and less subsoil root mass throughout the growing season that limited access to water in the subsoil and also reduced grain yield. In contrast, the other varieties increased amount of root growth in subsoil so that obtain water, especially when the topsoil moisture was low.

Tables S4, S5, S6 and S7 show that root influence on grain yield via effects on other physiological properties so that the plant can overcome on stress. This subject indicated that root features are effective on yield and other morphological traits of wheat. Value of correlation between variables reduced with increasing stress which caused insignificant relationships between variables. Atta et al. (2013) reported the high correlation was seen between roots with wheat yield in lower depths. Leilah (2005) found variables such as the panicle number, grain weight, and biological yield were effective on grain yield of wheat. Zhang et al. (2018) said that a change in any agronomic traits (such as plant height, panicle number per unit area, the grain number per panicle, 1000-grain weight, the panicle length and filled grain percentage) under drought conditions varies the final wheat yield. Ahmadizadeh et al. (2012) reported that there was high correlation between grain yield, Tillers number, Plant Height, Spike length and Peduncle Length. High significant correlation coefficient was seen between grain yield and Plant height, number of tillers per plant, number of spikes per plant and biomass (Zarei et al. 2013). Hosseini et al. (2016) stated that improvement of root growth caused enhance grain yield of wheat.

The biplot charts were shown according to the first and second components at all stress levels in Fig. S1. The biplot plot showed that with increasing the stress, the traits and genotypes were changed base on the first and second components. The location of $\mathrm{PH}$, SDM, and PDL traits in biplot charts showed with higher stress levels had more variable than other traits. Also, changing the position of genotypes with increasing drought stress indicates a different reaction of genotypes to stress so that these genotypes are associated with certain traits at each stress level. 


\section{Conclusion}

Drought stress affected on different parts of plant and the plant for contrast with stress, instead of increasing yield, extends the root system to compensate loss moisture. As a result, large amounts of energy and dry matter are used to produce roots and reduce the yield. One of the managements that has been used to prevent from decline yield in this research is the selection of suitable varieties. N-87-20 variety compared to other wheat varieties, significantly improved grain yield. Root system in this variety was more expansion relative to other varieties and according to the results of this research (correlation), root system under drought stress significantly affected on other morphological characteristics and wheat yield. Based on the principal component analysis, it was shown that Total Root Volume, grain yield, plant height and biological yield traits had a stronger association with N-87-20 variety and played an important role in the resistance of this variety to drought stress. In the future research, effect of soil organic and inorganic modifiers on soil moisture content and resistance to drought stress can be investigated.

\section{References}

Ahmadizadeh, M., Shahbazi, H. 2012. Assessment relationship between agro-morphological traits and grain yield in bread wheat genotypes under drought stress condition. Afr. J. Biotechnol. 11(35):8698-8704.

Atta, B.M., Mahmood, T., Trethowan, T.M. 2013. Relationship between root morphology and grain yield of wheat in north-western NSW, Australia. Aust. J. Crop Sci. 7(13):2108.

Budak, H., Kantar, M., Kurtoglu, K.Y. 2013. Drought Tolerance in Modern and Wild Wheat. The Scientific World Journal, Review Article. 1-16. http://dx.doi.org/10.1155/2013/548246

Cuenca, R.H. 1989. Irrigation system design-an engineering approach, 1st edn. Prentice Hall, Inc., Englewood Cliffs, New Jersey, p. 552.

Dolatabadian, A., Sanavy, S.A.M.M., Ghanati, F., Gresshoff, P.M. 2012. Morphological and physiological response of soybean treated with the microsymbiont Bradyrhizobium japonicum pre-incubated with genistein. S. Afr. J. Bot. 79:9-18.

Ehdaie, B., Layne, A.P., Waines, J.G. 2012. Root system plasticity to drought influences grain yield in bread wheat. Euphytica 186:219-232.

Fang, Y., Du, Y., Wang, J., Wu, A., Qiao, S., Xu, B., Chen, Y. 2017. Moderate drought stress affected root growth and grain yield in old, modern and newly released cultivars of winter wheat. Front. Plant Sci. 8(672): 1-14 doi: 10.3389/fpls.2017.00672.

Farooq, M., Hussain, M., Kadambot. H., Siddiqe, M. 2014. Drought stress in wheat during flowering and grain filling periods. Crit. Rev. Plant Sci. 33:331-349.

Guendouz, A., Djoudi, M., Guessoum, S., Maamri, K., Hannachi, A., Fellahi, Z., Hafsi, M. 2014. Genotypic and phenotypic correlations among yield and yield components in durum wheat (Triticum durum Desf.) under different water treatments in Eastern Algeria. Annual Research \& Review in Biology 4(2):432-442.

Hayat, Sh., Hayat, Q., Nasser Alyemeni, Shafi Wani, A., Pichtel, J., Ahmad, A. 2012. Role of proline under changing environments. Plant Signal Behav. 7(11):1456-1466.

Hosseini, M., Movahedi Naeini, S.A.R., Dehghani, A.A., Khaledian, Y. 2016. Estimation of soil mechanical resistance parameter by using particle swarm optimization, genetic algorithm and multiple regression methods. Soil and Tillage Research 157:32-42.

Kano, M., Inukai, Y., Kitano, H., Yamauchi, A. 2011. Root plasticity as the key root trait for adaptation to various intensities of drought stress in rice. Plant Soil 342:117-128.

Keshavarza, H., Sadegh Ghol Moghadamm, R. 2017. Seed priming with cobalamin (vitamin B12) provides significant protection against salinity stress in the common bean. Rhizosphere 3:143-149. 
Khakwani, A.A., Dennett, M.D., Munir, M., Abid, M. 2012. Growth and yield response of wheat varieties to water stress at booting and anthesis stages of development. Pak. J. Bot. 44(3):879-886.

Learnmore, M., Shimelis, H., Dube, E., Laing, M.D., Tsilo, T. 2016. Breeding wheat for drought tolerance: Progress and technologies. Journal of Integrative Agriculture 15(5):935-943.

Leilah, A.A., Alkhateeb, S.A. 2005. Statistical analysis of wheat yield under drought conditions. J. Arid Environ. 61:483-496.

Lonbani, M., Arzani, A. 2011. Morpho-physiological traits associated with terminal drought stress tolerance in triticale and wheat. Agronomy Research 9(1-2):315-329.

Othmani, A., Rezgui, M., Cherif, S., Mouelhi, M., Melki, M. 2015. Effects of water regimes on root and shoot growth parameters and agronomic traits of Tunisian durum wheat (Triticum durum Desf.). J. New Sci. Agric. Biotechnol. 18:695-702.

Palta, J.A., Chen, X., Milroy, S.P., Rebetzke, G.J., Dreccer, M.F., Watt, M. 2011. Large root systems: are they useful in adapting wheat to dry environments? Funct. Plant Biol. 38:347-354.

Placido, D.F., Campbell, M.T., Folsom, J.J., Cui, X., Kruger, G.R., Baenziger, P.S., Walia, G. 2013. Introgression of novel traits from a wild wheat relative improves drought adaptation in wheat. Plant Physiol. 161:1806-1819.

Reynolds, M.P., Mujeeb-Kazi, A., Sawkins, M. 2005. Prospects for utilising plant-adaptive mechanisms to improve wheat and other crops in drought- and salinity-prone environments. Ann. Appl. Biol. 146:239-259.

Sun, Y.Y., Wang, X.L., Wang, N., Chen, Y.L., Zhang, S.Q. 2014. Changes in the yield and associated photosynthetic traits of dry-land winter wheat (Triticum aestivum L.) from the 1940s to the 2010s in Shaanxi Province of China. Field Crops Res. 167:1-10.

Wasson, A.P., Richards, R.A., Chatrath, R., Misra, S.C., Prasad, S.V.S., Rebetzke, G.J., Kirkegaard, J.A., Christopher, J., Watt, M. 2012. Traits and selection strategies to improve root systems and water uptake in water-limited wheat crops. J. Exp. Bot. 63:3485-3498.

Zarei, L., Cheghamirza, K., Farshadfar, E. 2013. Evaluation of grain yield and some agronomic characters in durum wheat (Triticum turgidum L.) under rainfed conditions. Aust. J. Crop Sci. 7(5):609-617.

Zhang, J., Zhang, S., Cheng, M., Jiang, H., Zhang, X., Peng, C., Jin, J. 2018. Effect of drought on agronomic traits of rice and wheat: A meta-analysis. Int. J. Env. Res. Pub. He. 15(5):1-14.

Zhu, L., Zhang, D.Y. 2013. Donald's Ideotype and growth redundancy: A pot experimental test using an old and a modern spring wheat cultivar. PLoS One 8(7):e70006.

\section{Electronic Supplementary Material (ESM)}

Electronic Supplementary Material (ESM) associated with this article can be found at the website of CRC at http://www.akademiai.com/content/120427/

Electronic Supplementary Table S1. Analysis of variance (mean squares) for the effects of irrigation treatments and varieties on some morphological traits, yield and yield components in wheat plants

Electronic Supplementary Table S2. Effect of irrigation regime on some morphological traits in wheat

Electronic Supplementary Table S3. Effect of varieties on some morphological traits, yield and yield components in wheat

Electronic Supplementary Table S4. Interaction of Irrigation regime $\times$ cultivars on some morphological traits of wheat

Electronic Supplementary Table S5. Correlation coefficients between different parameters in some wheat cultivars at no stress condition 
Electronic Supplementary Table S6. Correlation coefficients between different parameters in some wheat cultivars at mild stress condition

Electronic Supplementary Table S7. Correlation coefficients between different parameters in some wheat cultivars at moderate stress condition

Electronic Supplementary Table S8. Correlation coefficients between different parameters in some wheat cultivars at severe stress condition

Electronic Supplementary Table S9. The results of the principal components analysis based on different parameters in some wheat cultivars at different stress condition

Electronic Supplementary Figure S1. Principal component analysis of Triticum aestivum L. under control (A), mild (B), moderate (C) and severe drought-stressed (D) conditions. Loading of variables (1: N-87-20; 2: Gonbad; 3: Morvarid; 4: N-91-8; 5: Kouhdasht; 6: Karim; 7: Ghabous; 8: Aftab). Percentage variation explained by each component is given next to the axis. RD: Root depth; TRDM: Total Root Dry Matter; TRV: Total Root Volume; SDM: Shoot Dry Matter; R/SH: Root/shoot ratio; PH: Plant Height; PDL: Peduncle Length; SL: Spike length; FTN: Number of Tiller; GW: 1000 grain weight; GY: Grain Yield; BY: Biomass Yield 
